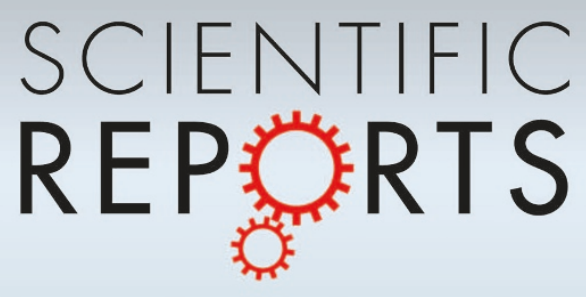

OPEN

SUBJECT AREAS:

FLUORESCENT PROBES

BIOANALYTICAL CHEMISTRY

DNA

Received

1 October 2013

Accepted

17 November 2014

Published

4 December 2014

Correspondence and requests for materials should be addressed to J.H. (jmhu@whu.edu. $\mathrm{cn})$ or R.P. (ripei2011@sinano. ac.cn)

\section{Multiple types of logic gates based on a single G-quadruplex DNA strand}

\author{
Yahui Guo ${ }^{1,2}$, Lu Zhou' ${ }^{1}$ Lijun Xu' , Xiaodong Zhou' ${ }^{2}$, Jiming Hu² \& Renjun Pei ${ }^{1}$
}

'Key Laboratory of Nano-Bio Interface, Division of Nanobiomedicine, Collaborative Innovation Center of Suzhou Nano Science and Technology, Suzhou Institute of Nano-Tech and Nano-Bionics, Chinese Academy of Sciences, Suzhou, 215123 (China), ${ }^{2}$ Key Laboratory of Analytical Chemistry for Biology and Medicine (Ministry of Education), College of Chemistry \& Molecular Sciences, Wuhan University, Wuhan, 430072 (China).

In this work, we demonstrate the use of a single DNA strand and G-quadruplex-specific dye NMM as a label-free switch for the construction of series of basic logic gates (YES, NOT, OR, INHIBIT, NOR, AND). The simple GT-rich sequence could be used to interact with several molecules $\left(\mathrm{K}^{+}\right.$, thrombin, $\mathrm{Hg}^{2+}$, and $\mathrm{Pb}^{2+}$ ) to form different structures that can be distinguished by the label-free dye NMM. Our study showed that a single G-qudruplex DNA strand can function as multiple types of one-input and two-input logic gates with different combinations of input molecules.

D NA is an information coding polymer. So it is an ideal candidate for information storage ${ }^{1}$ and molecular computation ${ }^{2}$. After the DNA computation was proposed by Adleman in $1994^{3}$, numerous efforts have been made to construct DNA logic gates ${ }^{4-7}$ and computation circuits $s^{8-12}$ through a bottom-up strategy ${ }^{13}$. Recently, the study of G-quadruplex-specific dyes with light-up fluorescence ${ }^{14,15}$ provided a simple, label-free and cost-effective signal-producing approach to construct DNA-based logic gates ${ }^{12}$. Our goal here is to show that this approach can be extended by using a single G-quadruplex DNA strand from creating a single type of logic gate with two inputs to multiple types of logic gates with different combinations of several input molecules.

G-quadruplexes are unique structures formed by G-rich nucleic acid sequences and based on stacked arrays of G-quartets connected by Hoogsteen-type base pairing. These structures are further stabilized and recognized by the presence of monovalent cations (especially $\left.\mathrm{K}^{+}\right)^{16,17}$ and some biological molecules (such as thrombin) ${ }^{18}$. Nmethyl mesoporphyrin IX (NMM) is an unsymmetrical anionic porphyrin characterized by a pronounced structural selectivity for G-quadruplexes but not for duplexes, triplexes, or single-stranded forms. The fluorescence of NMM is very weak, but exhibits a dramatic enhancement upon binding to G-quadruplex DNA ${ }^{19}$. This behavior is the same as the other quadruplex-specific dyes ${ }^{20}$. This allows us to utilize NMM as a label-free fluorescent probe to indicate the formation of G-quadruplex structure and monitor its conformational change. For implementing the complicated computation circuits and networks, label-free and more modular computation units are desirable. The formation of G-quadruplex could be not only triggered by many metal ions, some small molecules and proteins, but also regulated by changes of DNA secondary structure through dsDNA hybridization and aptamer binding ${ }^{21-26}$, which could bring various design strategies and indicate a great potential in label-free DNA computation. As a powerful technical tool in DNA computation, the employment of Gquadruplex as the logic component might promote the development of DNA computation in a more economical, versatile and modular way.

Herein, a thymine-rich and guanine-rich DNA oligomer, which could transform to G-quadruplex in the presence of several molecules, was employed to construct a series of basic logic gates with label-free fluorescent output. Fig. 1 shows multiple types of label-free fluorescent logic gates based on this single sequence, which could perform YES, NOT, OR, INHIBIT, NOR and AND logic operations under the action of different inputs.

\title{
Results
}

The system contained a GT-rich ssDNA (GT24) and a G-quadruplex specific fluorescent dye NMM. The fluorescence intensity of NMM was negligible when the GT24 was in "loose" status; however, in the presence of $\mathrm{K}^{+}$or thrombin, GT24 transformed to a rigid G-quadruplex structure, which brought out a significant fluorescence increase of NMM. As shown in Fig. 2, the fluorescence intensity of NMM-GT24 complex increased gradually with the increasing concentrations of $\mathrm{K}^{+}$and thrombin, showing a linear dependence (Fig. S1\&S2). Since G-quadruplex has the characteristic peak near $290 \mathrm{~nm}$ in CD spectra, the formation of G-quadruplex was 


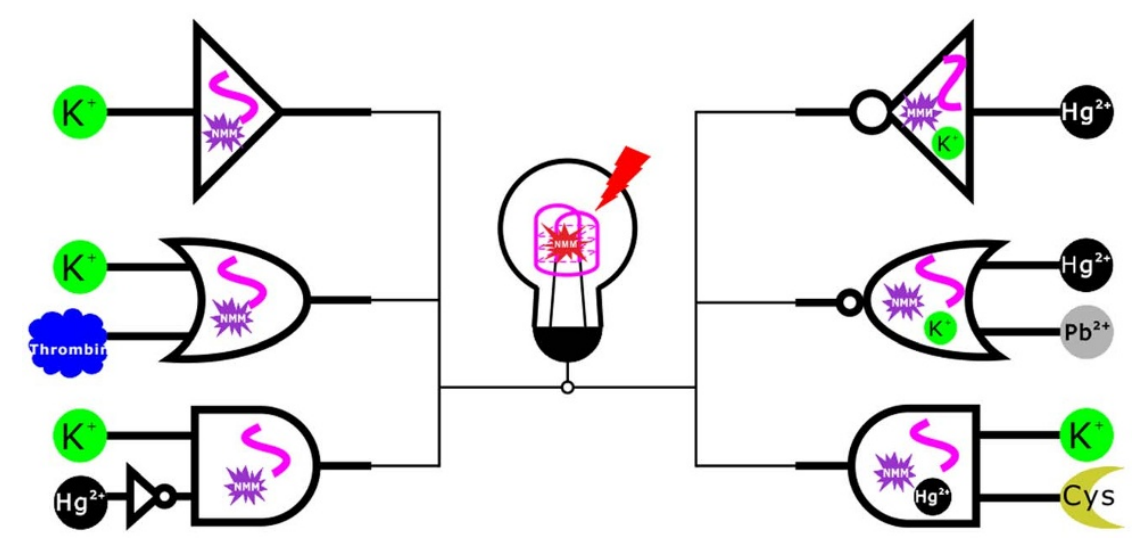

Figure 1 | Schematic representation of multiple label-free fluorescent logic gates based on a single G-quadruplex DNA.

further validated by the circular dichroism (Fig. S3) ${ }^{27,28}$. The fluorescence intensity was normalized throughout the experiment, the background fluorescence signal (NMM-GT24 complex) at $610 \mathrm{~nm}$ was defined as 0.1 , signals higher than 10 -fold background $(>1.0$ a.u.) was defined as output "1", otherwise, signals lower than 0.4 a.u. as output " 0 ".

Based on aforementioned fact, we first designed YES and OR logic gates which employed NMM and GT24 as components and regarded $\mathrm{K}^{+}$and thrombin as inputs (Fig. 3.a). For inputs, the presence of $\mathrm{K}^{+}$ or thrombin was defined as the " 1 " state. The presence of $\mathrm{K}^{+}$contributed to the transformation of GT24 from a relaxed state to a taut state, turning on the fluorescence of NMM from "Off" state $(>1.0$
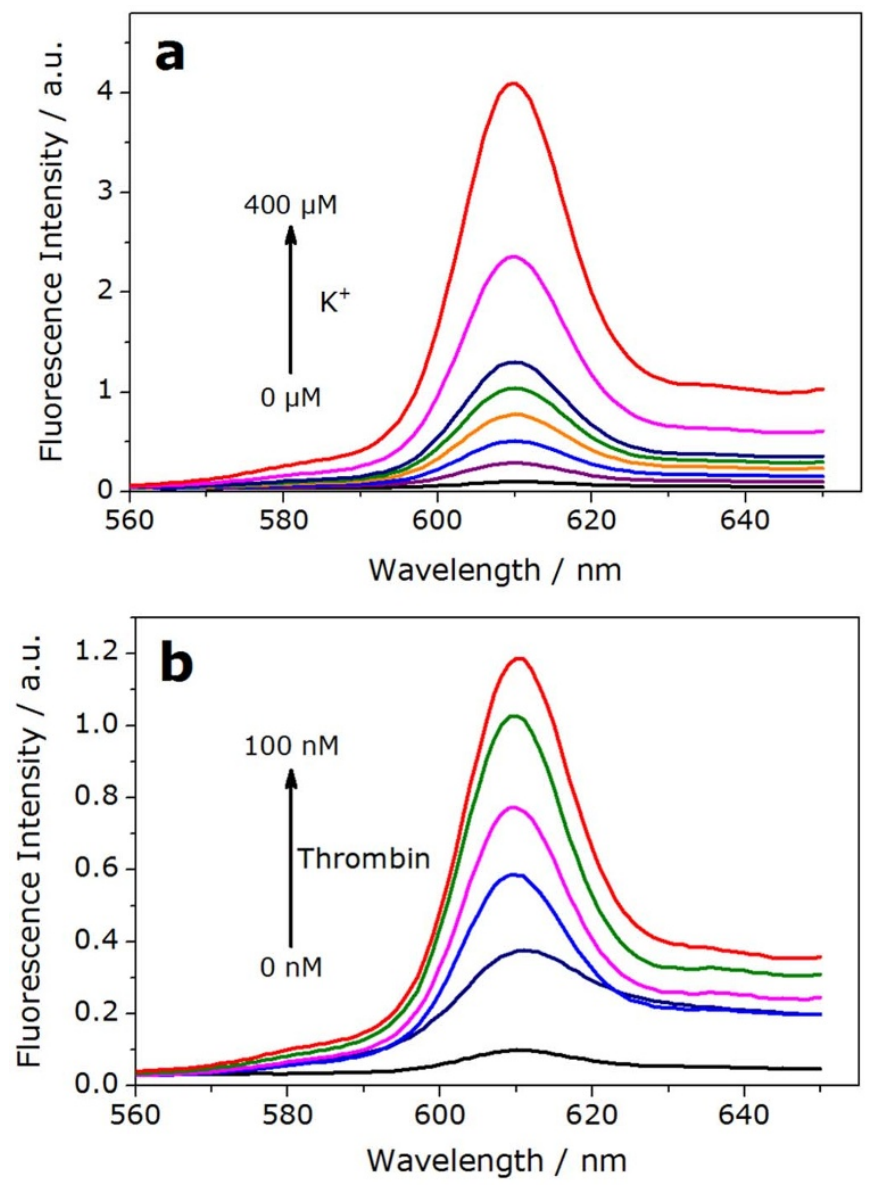

Figure 2 Fluorescence emission spectra of NMM-GT24 complex as a function of various concentrations of $\mathrm{K}^{+}(\mathrm{a})$ and thrombin(b). a.u., output $=1$ ), which was defined as the simplest YES logic gate (Fig. 3.b). In the OR logic operation, the presence of both inputs (1/1) or the presence of either input $(0 / 1,1 / 0)$ could cause a fluorescence enhancement in $610 \mathrm{~nm}(>1.0$ a.u., output $=1)$; while in the absence of both inputs $(0 / 0)$, the system gave a low fluorescence signal due to the loose state of GT24 ( $<0.4$ a.u., output=0) (Fig. 3.c).

In the presence of $\mathrm{Hg}^{2+}$, GT24 was transformed from the $\mathrm{K}^{+}$activated G-quadruplex into a hairpin structure, due to the formation of a stable T-Hg-T mismatch ${ }^{29-32}$. Consequently, as shown in Fig. 4.a \& S4.a, with the increasing concentration of $\mathrm{Hg}^{2+}$, the fluorescence of NMM was restored to the low bulk value due to the release of NMM from GT24. The disappearing peak in $290 \mathrm{~nm}$ in circular dichroism further validated the deformation of G-quadruplex structure mediated by $\mathrm{Hg}^{2+}$ (Fig. S5). A NOT gate performs logical negation on its input. In other words, if the input is present, then the output will be false ("0"). Similarly, the absence of input results in a true output(" 1 "). The logic of an INHIBIT gate is that the output is " 1 " only when one particular input is present when the second input is not present. Established on these properties, this GT24 sequence with $\mathrm{K}^{+}$could be used to construct NOT logic gate by using the addition of $\mathrm{Hg}^{2+}$ as the input. And the INHIBIT logic gate was constructed with GT24 by using the addition of $\mathrm{K}^{+} / \mathrm{Hg}^{2+}$ as the inputs (Fig. 5). In the NOT gate, the output is " 1 " when the input $\left(\mathrm{Hg}^{2+}\right)$ was "0" (Fig. 5.b). In the INHIBIT gate, the output was "1" only upon the addition of $\mathrm{K}^{+}$(input $\left.=1 / 0\right)$, while it was " 0 " for all other combination of inputs $(0 / 0,0 / 1,1 / 1)$ (Fig. 5.c).

$\mathrm{Pb}^{2+}$ competitively binds to the $\mathrm{K}^{+}$-stabilized G-quadruplex to form more compact DNA fold ${ }^{33,34}$. As judged by the $\mathrm{M}-\mathrm{O} 6$ bond length, O6-O6 diagonal distance and inter-tetramer separation, structure analysis indicated that the divalent $\mathrm{Pb}^{2+}$ templates a smaller G-quadruplex than $\mathrm{K}^{+}$does ${ }^{35}$. As a result, the $\mathrm{Pb}^{2+}$-stabilized Gquadruplex prohibits the formation of the complex of G-quadruplex with $\mathrm{NMM}^{36}$, which resulted in fluorescence decrease (Fig. 4.b). This enabled us to design a NOR gate, in which $\mathrm{Hg}^{2+}$ and $\mathrm{Pb}^{2+}$ serve as inputs, in the initial state, the enhanced fluorescence signal was observed since NMM bound with the $\mathrm{K}^{+}$-activated $\mathrm{G}$-quadruplex. In the presence of either or both inputs $(0 / 1,1 / 0,1 / 1)$, the signal of fluorescence decreased significantly $(<0.4$ a.u., output $=0)$, which was in accord with the proper execution of a NOR logic gate (Fig. 5.d).

Cysteine is a strong $\mathrm{Hg}^{2+}$ binder that can withdraw $\mathrm{Hg}^{2+}$ ions from the $\mathrm{T}-\mathrm{Hg}-\mathrm{T}$ complex and sequester $\mathrm{Hg}^{2+}$ ions in the form of stable $\mathrm{Hg}$-Cys complexes ${ }^{37}$. So we constructed an AND logic gate with $\mathrm{Hg}^{2+}$ and GT24 as components and employed $\mathrm{K}^{+}$and cysteine as inputs. As shown in Fig. 6.a, initially the sequence held the structure in the T$\mathrm{Hg}-\mathrm{T}$ state, then the cooperative binding of cysteine with $\mathrm{Hg}^{2+}$ turned it back into a quadruplex structure with the assistant of monovalent cation $\mathrm{K}^{+}$, therefore the signal intensity of NMM was enhanced. Fig. 6b. shows that the enhanced fluorescence intensity depended on the increasing concentration of Cys. Hence, like in a 

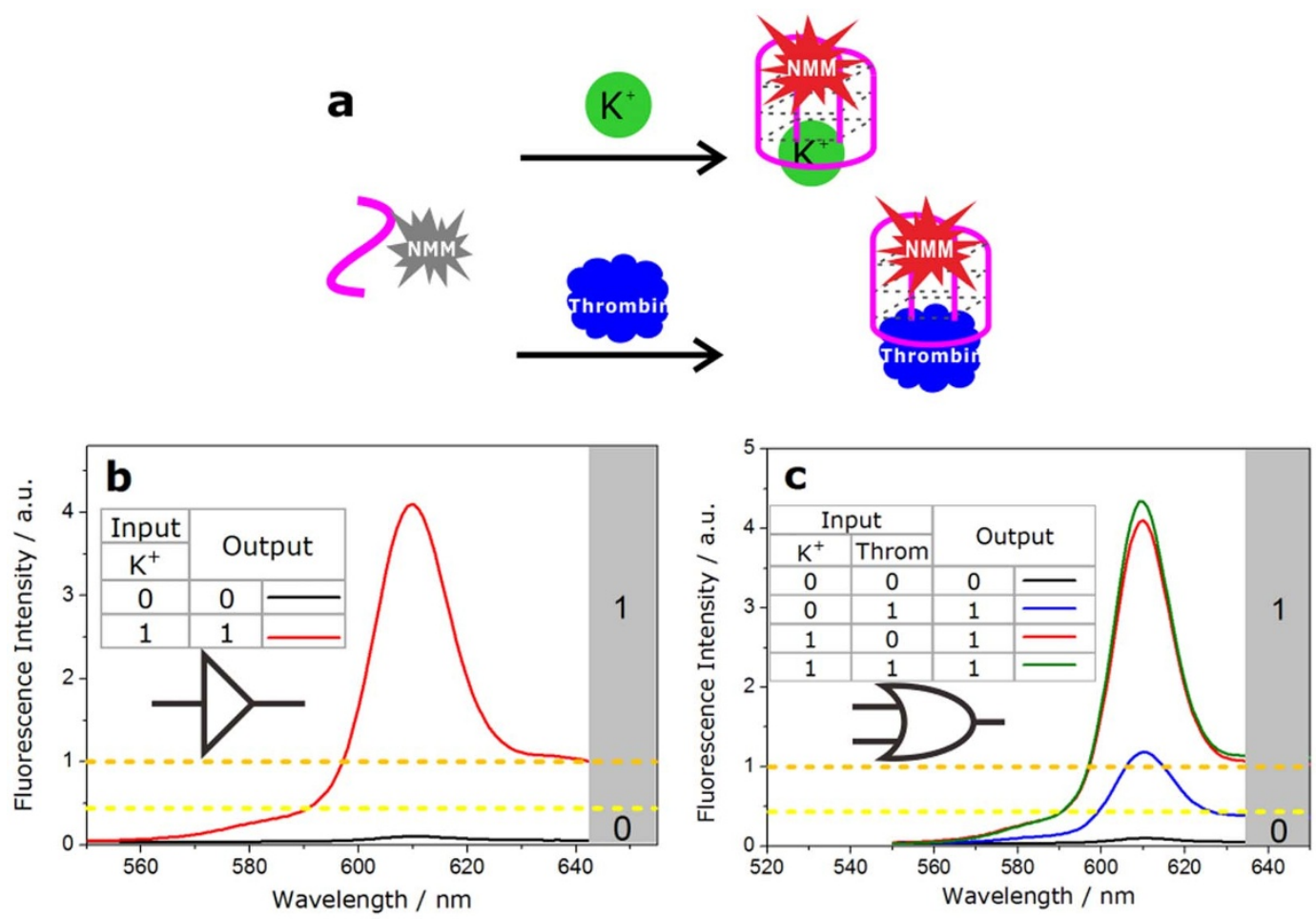

Figure 3 YES and OR logic gates. (a), Scheme of the allosteric G-quadruplex induced by $\mathrm{K}^{+}(10 \mathrm{mM})$ and thrombin (100 nM). (b), Fluorescence spectra of the NMM-GT24 complex in the presence or absence of input and the truth table of YES logic gate. (c), Fluorescence spectra of the NMM-GT24 complex in all combinations of two inputs and the truth table of OR logic gate.

typical AND operation, the output was "1" (enhanced FI $>1.0$ a.u.) only when both $\mathrm{K}^{+}$and cysteine were added into the system (input $=1 / 1$ ), and it was " 0 " when only one of them or neither was added (input $=0 / 0,0 / 1,1 / 0$; Fig. 6.c).

\section{Discussion}

The light-up fluorescence from the interaction between NMM and G-quadruplex provided a label-free approach to indicate the formation of G-quadruplex structure and monitor its conformational change. G-quadruplex-forming sequence is a simple and cost-effective signal-producing logic component to construct DNA-based logic gates. The GT-rich sequence GT24 in this study could interact with several molecules (potassium, thrombin, mercury, lead and cysteine), which could act as a versatile recognition unit in multiple types of logic gates with different combinations of several input molecules as showed. This might be regarded as particular case since the single GT24 DNA in this study contains only G-rich quadruplexforming segments and $\mathrm{T}$-rich $\mathrm{Hg}^{2+}$-binding segments, but this technical report using a single strand could give us a clue that we might embed multiple aptamer sequences in one DNA strand to undertake programmable computing tasks. There have been reports on artificial aptazyme-based riboswitch by inserting more than one RNA aptamer sequence, which bind specifically to their target ligands, into the $5^{\prime}$ UTR of mRNA, making a cell to be the arithmetic unit ${ }^{38}$. Aptamers could be modulated by interactions between aptamers and their targets including various ions, molecules, even cells ${ }^{39-41}$, which brings more input elements in DNA computation and indicates the applications of intelligent diagnosis or drug delivery in biomedicine $\mathrm{e}^{42-44}$. The introduction and integrating of aptamer sequences in DNA computation would make DNA computation in a more versatile and practical way.

In summary, we have successfully demonstrated that the single GT-rich DNA sequence can be used as label-free fluorescent switch by binding with G-quadruplex-specific dye NMM for constructing multiple types of DNA logic gates. Our study suggests a
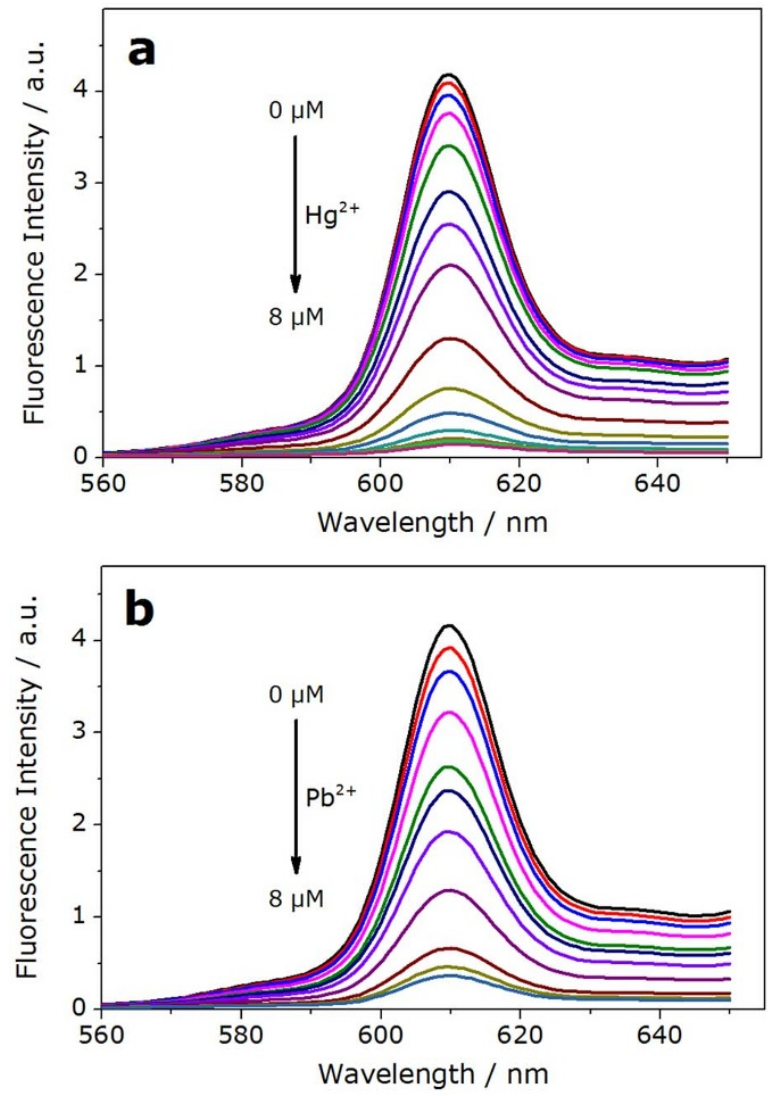

Figure $4 \mid$ (a), Fluorescent spectra of the NMM-GT24 complex with $\mathrm{K}^{+}$ $(10 \mathrm{mM})$ upon the addition of $\mathrm{Hg}^{2+}(0,0.05,0.1,0.2,0.4,0.6,0.8,1.0,2.0$, 3.0, 4.0, 5.0, 6.0, 7.0, 8.0 $\mu \mathrm{M})$. (b), Fluorescent spectra of the NMM-GT24 complex with $\mathrm{K}^{+}(10 \mathrm{mM})$ upon the addition of $\mathrm{Pb}^{2+}(0,0.1,0.2,0.4,0.6$, $0.8,1.0,2.0,4.0,6.0,8.0 \mu \mathrm{M})$. 
a
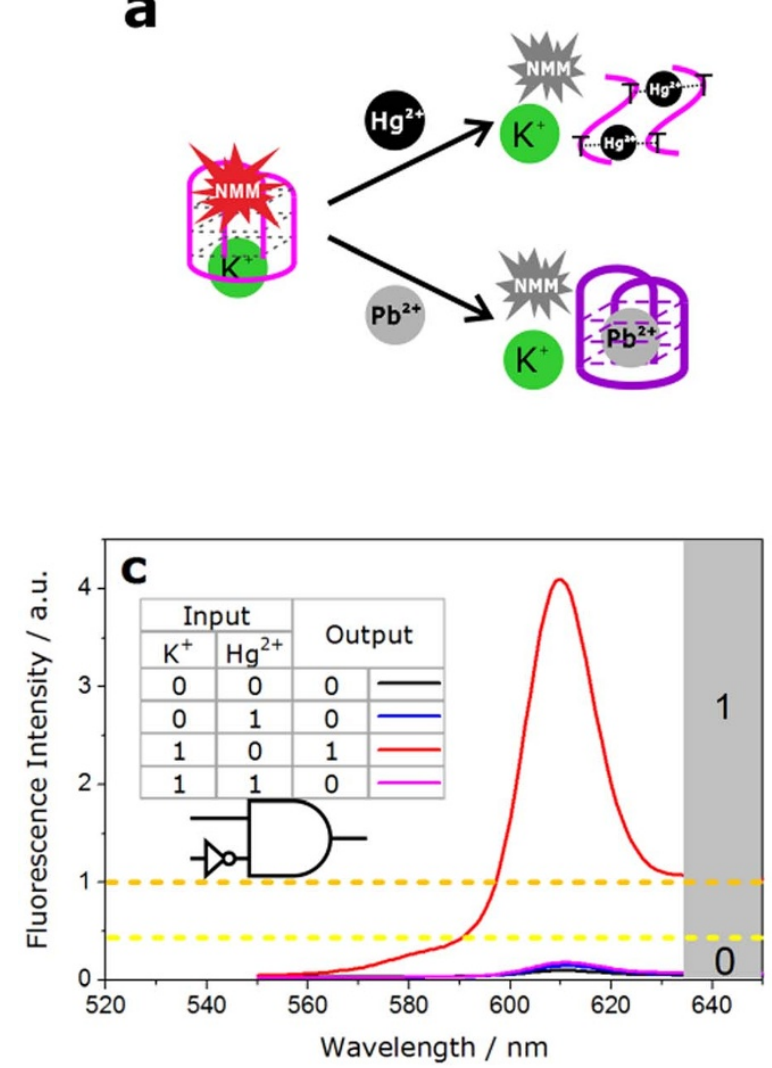
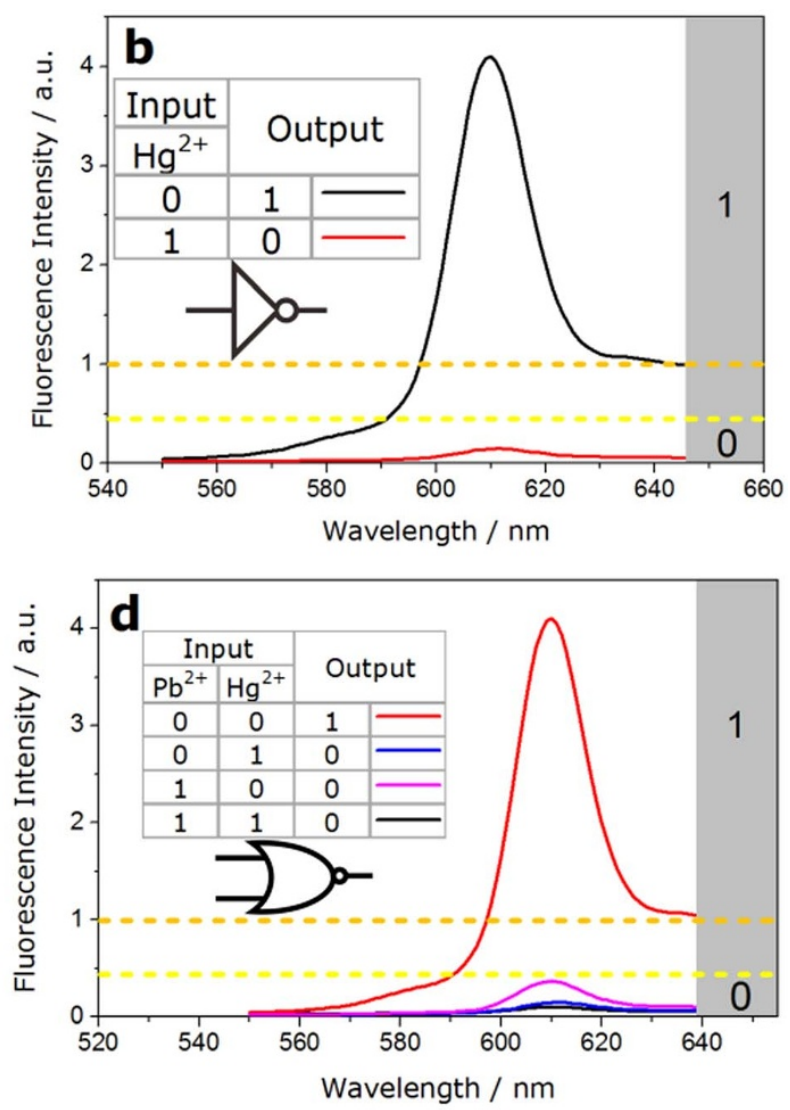

Figure 5 NOT, INHIBIT and NOR logic gates. (a), Graphic illustration of the NMM-GT24 complex with $\mathrm{K}^{+}(10 \mathrm{mM})$ as a switch by employing $\mathrm{Hg}^{2+}(10 \mu \mathrm{M})$ and $\mathrm{Pb}^{2+}(10 \mu \mathrm{M})$ as inputs. (b), Fluorescence spectra of the NMM-GT24 complex with $\mathrm{K}^{+}$in the presence or absence of $\mathrm{Hg}^{2+}$ and the truth table of NOT logic gate. (c), Fluorescence spectra of the NMM-GT24 complex in the presence of all input combinations of $\mathrm{K}^{+}$and $\mathrm{Hg}^{2+}$ and the truth table of INHIBIT logic gate. (d), Fluorescence changes for NMM-GT24 complex with $\mathrm{K}^{+}$in the presence of all input combinations of $\mathrm{Pb}^{2+}$ and $\mathrm{Hg}^{2+}$ and the truth table of NOR logic gate.

a
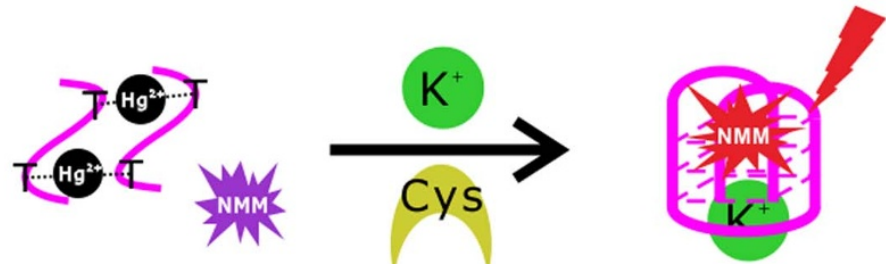
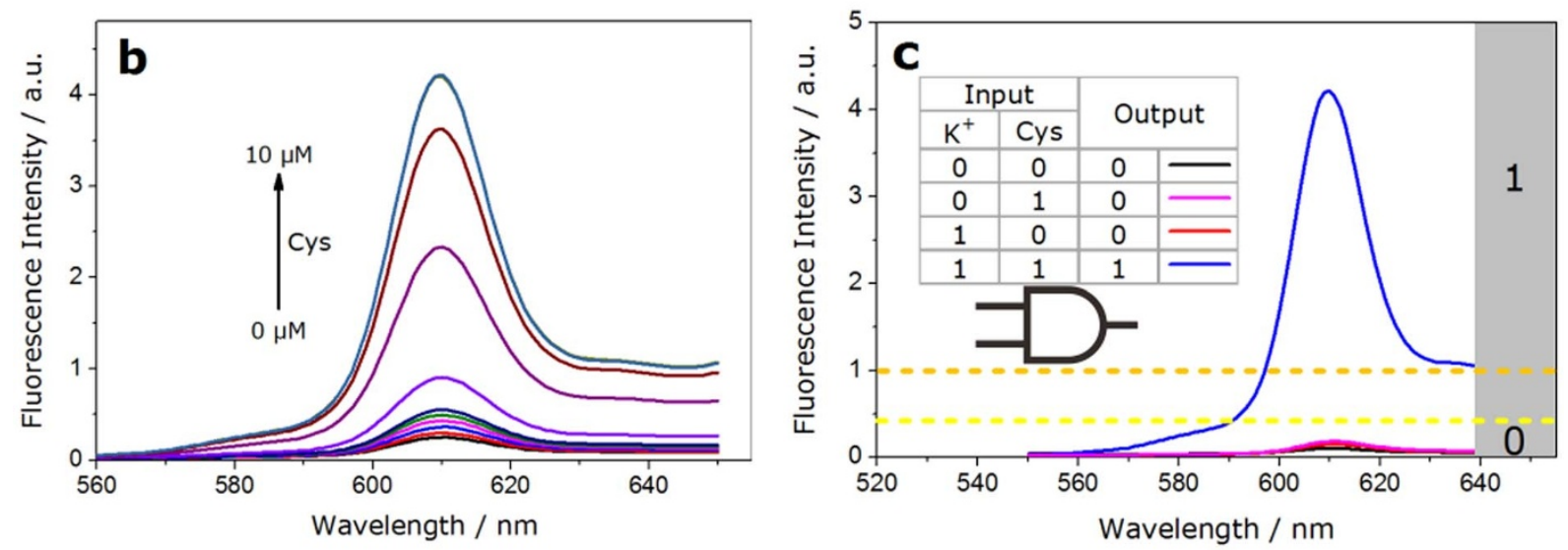

Figure 6 | AND logic gate. (a), Graphic illustration of AND logic gate switched by $\mathrm{K}^{+}$and cysteine as two inputs. (b), Fluorescence titration of the NMM-GT24 complex (with $10 \mathrm{mM} \mathrm{K}^{+}$and $8 \mu \mathrm{M} \mathrm{Hg}^{2+}$ in solution) in the presence of various concentrations of cysteine $(0,0.2,0.4,0.6,0.8,1.0,2.0,4.0$, $6.0,8.0,10 \mu \mathrm{M})$. (c), Fluorescence spectra in the presence of all input combinations and the truth table of AND logic gate. 
strategy that one could insert different aptamer domains into a single oligonucleotide to undertake more complex computing functions.

\section{Methods}

Materials. Oligonucleotide (GT24: 5'-GGGTTTTGGGTTTTGGGTTTTGGG-3') was purchased from Invitrogen Biotechnology Co., Ltd. (Shanghai, China). Nmethyl mesoporphyrin IX (NMM) was bought from J\&K Scientific Ltd. (Beijing, China) and other chemicals were of analytical grade purity and purchased from Sigma-Aldrich (St. Louis, U.S.A.). All measurements were performed in $20 \mathrm{mM}$ Tris- $\mathrm{HCl}, 10 \mathrm{mM} \mathrm{MgCl}$ and $\mathrm{pH}$ 7.5. The concentration of GT24 and NMM was $0.5 \mu \mathrm{M}$ throughout the experiments. Computations for YES, OR logic gates were completed in $10 \mathrm{~min}$, and for NOT, INHIBIT, NOR each input combination was incubated for $0.5 \mathrm{~h}$, in the AND logic operation the fluorescence intensity was recorded after $1.5 \mathrm{~h}$

Instruments. Ultrapure water from MILLI-Q Synthesis (Millipore Int., Molsheim, France) source was used throughout the experiments. The concentration of NMM was measured on a UV-2550 spectrophotometer (SHIMADZU, Japan). Fluorescence spectra data were collected with an F-4600 fluorescence spectrophotometer (Hitachi Co. Ltd., Japan) equipped with a Xenon lamp excitation source. Slit widths for the excitation (the excited wavelength $399 \mathrm{~nm}$ ) and emission were set at 10 and $10 \mathrm{~nm}$ respectively. CD spectra were measured with a Chirascan dichrograph (Applied Photophysics Ltd) in $1 \mathrm{~cm}$ path length quartz. The scan speed was $50 \mathrm{~nm} \mathrm{~min}{ }^{-1}$ and bandwidth was $1 \mathrm{~nm}$.

1. Goldman, N. et al. Towards practical, high-capacity, low-maintenance information storage in synthesized DNA. Nature 494, 77-80 (2013).

2. Pei, R., Matamoros, E., Liu, M., Stefanovic, D. \& Stojanovic, M. N. Training a molecular automaton to play a game. Nat. Nanotechnol. 5, 773-777 (2010).

3. Adleman, L. M. Molecular computation of solutions to combinatorial problems. Science 266, 1021-1024 (1994).

4. Lake, A., Shang, S. \& Kolpashchikov, D. M. Molecular logic gates connected via DNA four way junctions. Angew. Chem. Int. Ed. 49, 4459-4462 (2010).

5. Freeman, R., Finder, T. \& Willner, I. Multiplexed analysis of $\mathrm{Hg}^{2+}$ and $\mathrm{Ag}^{+}$ions by nucleic acid functionalized $\mathrm{CdSe} / \mathrm{ZnS}$ quantum dots and their use for logic gate operations. Angew. Chem. Int. Ed. 48, 7818-7821 (2009).

6. Li, T., Zhang, L., Ai, J., Dong, S. \& Wang, E. Ion-tuned DNA/Ag fluorescent nanoclusters as versatile logic device. ACS Nano 5, 6334-6338 (2011).

7. Li, T., Ackermann, D., Hall, A. M. \& Famulok, M. Input-dependent induction of oligonucleotide structural motifs for performing molecular logic. J. Am. Chem. Soc. 134, 3508-3516 (2012).

8. Seelig, G., Soloveichik, D., Zhang, D. Y. \& Winfree, E. Enzyme-free nucleic acid logic circuits. Science 314, 1585-1588 (2006).

9. Qian, L. \& Winfree, E. Scaling up digital circuit computation with DNA strand displacement cascades. Science 332, 1196-1201 (2011).

10. Rudchenko, M. et al. Autonomous molecular cascades for evaluation of cell surfaces. Nat. Nanotechnol. 8, 580-586 (2013).

11. Li, W., Yang, Y., Yan, H. \& Liu, Y. Three-input majority logic gate and multiple input logic circuit based on DNA strand displacement. Nano Lett. 13, 2980-2988 (2013).

12. Zhu, J., Zhang, L., Li, T., Dong, S. \& Wang, E. Enzyme-free unlabeled DNA logic circuits based on toehold-mediated strand displacement and split G-quadruplex enhanced fluorescence. Adv. Mater. 25, 2440-2444 (2013).

13. Krishnan, Y. \& Simmel, F. C. Nucleic acid based molecular devices. Angew. Chem. Int. Ed. 50, 3124-3156 (2011).

14. He, H. Z, Chan, D. S., Leung, C. H. \& Ma, D. L. G-quadruplexes for luminescent sensing and logic gates. Nucleic Acids Res. 41, 4345-4359 (2013).

15. Largy, E., Granzhan, A., Hamon, F., Verga, D. \& Teulade-Fichou, M. P. Visualizing the quadruplex: from fluorescent ligands to light-up probes. Top. Curr. Chem. 330, 111-177 (2013).

16. Sen, D. \& Gilbert, W. Formation of parallel four-stranded complexes by guanine-rich motifs in DNA and its implications for meiosis. Nature 334, 364-366 (1988).

17. Williamson, J. R., Raghuraman, M. K. \& Cech, T. R. Monovalent cation-induced structure of telomeric DNA: the G-quartet model. Cell 59, 871-880 (1989).

18. Macaya, R. F., Schultze, P., Smith, F. W., Roe, J. A. \& Feigon, J. Thrombin-binding DNA aptamer forms a unimolecular quadruplex structure in solution. Proc. Natl. Acad. Sci. USA. 90, 3745-3749 (1993).

19. Arthanari, H., Basu, S., Kawano, T. L. \& Bolton, P. H. Fluorescent dyes specific for quadruplex DNA. Nucleic Acids Res. 26, 3724-3728 (1998).

20. Li, Y. \& Sen, D. A catalytic DNA for porphyrin metallation. Nat. Struct. Biol. 3, 743-747 (1996).

21. Kong, D. M., Guo, J. H., Yang, W., Ma, Y. E. \& Shen, H. X. Crystal violet-Gquadruplex complexes as fluorescent sensors for homogeneous detection of potassium ion. Biosens. Bioelectron. 25, 88-93 (2009).
22. Zhao, C., Wu, L., Ren, J. \& Qu, X. A label-free fluorescent turn-on enzymatic amplification assay for DNA detection using ligand-responsive G-quadruplex formation. Chem. Commun. 47, 5461-5463 (2011).

23. Guo, Y., Xu, P., Hu, H., Zhou, X. \& Hu, J. A label-free biosensor for DNA detection based on ligand-responsive G-quadruplex formation. Talanta 114, 138-142 (2013).

24. Guo, Y. et al. Label-free logic modules and two-layer cascade based on stem-loop probes containing a g-quadruplex domain. Chem. Asian. J. 9, 2397-2401 (2014).

25. Zhang, Z., Sharon, E., Freeman, R., Liu, X. \& Willner, I. Fluorescence detection of DNA, adenosine- $5^{\prime}$-triphosphate (ATP), and telomerase activity by zinc(II)protoporphyrin IX/G-quadruplex labels. Anal. Chem. 84, 4789-4797 (2012).

26. Li, D., Shlyahovsky, B., Elbaz, J. \& Willner, I. Amplified analysis of low-molecularweight substrates or proteins by the self-assembly of DNAzyme-aptamer conjugates. J. Am. Chem. Soc. 129, 5804-5805 (2007).

27. Li, T., Wang, E. K. \& Dong, S. J. Parallel G-quadruplex-specific fluorescent probe for monitoring DNA structural changes and label-free detection of potassium ion. Anal. Chem. 82, 7576-7580 (2010).

28. Yuminova, A. V., Spiridonova, V. A., Arutyunyan, A. M. \& Kopylov, A. M. Structural study of thrombin binding DNA aptamers by the circular dichroism. Dokl. Biochem. Biophys. 442, 36-38 (2012).

29. Miyake, Y. et al. MercuryII-mediated formation of thymine-HgII-thymine base pairs in DNA duplexes. J. Am. Chem. Soc. 128, 2172-2173 (2006).

30. Li, T., Dong, S. \& Wang, E. Label-free colorimetric detection of aqueous mercury ion $\left(\mathrm{Hg}^{2+}\right)$ using $\mathrm{Hg}^{2+}$-modulated G-quadruplex-based DNAzymes. Anal. Chem 81, 2144-2140 (2009)

31. Wang, Z., Heon, L. J. \& Lu, Y. Highly sensitive "turn on" fluorescent sensor for $\mathrm{Hg}^{2+}$ in aqueous solution based on structure-switching DNA. Chem. Commun. 45, 6005-6007 (2008).

32. Zhao, J. et al. $\mathrm{A} \mathrm{Hg}^{2+}$-mediated label-free fluorescent sensing strategy based on Gquadruplex formation for selective detection of glutathione and cysteine. Analyst. 138, 1713-1718 (2013).

33. Smirnov, I. \& Shafer, R. H. Lead is unusually effective in sequence-specific folding of DNA. J. Mol. Biol. 296, 1-5 (2000).

34. Li, T., Wang, E. \& Dong, S. Potassium-lead-switched G-quadruplexes: a new class of DNA logic gates. J. Am. Chem. Soc. 131, 15082-15083 (2009).

35. Kotch, F. W., Fettinger, J .C. \& Davis, J. T. A lead-filled G-quadruplex: insight into the G-quartet's selectivity for $\mathrm{Pb}^{2+}$ over $\mathrm{K}^{+}$. Org. Lett. 2, 3277-3280 (2000).

36. Wang, X. Y. et al. A novel molecular logic system based on lead-induced substitution of potassium from a G-quadruplex as a fluorescent lead sensor. Anal. Methods 5, 5597-5601 (2013)

37. Stricks, W. \& Kolthoff, I. M. Reactions between mercuric mercury and cysteine and glutathione - apparent dissociation constants, heats and entropies of formation of various forms of mercuric mercapto-cysteine and mercaptoglutathione. J. Am. Chem. Soc. 75, 5673-5681 (1953).

38. Win, M. N. \& Smolke, C. D. Higher-order cellular information processing with synthetic RNA devices. Science 322, 456-460 (2008)

39. Tan, W., Donovan, M. J. \& Jiang, J. Aptamers from cell-based selection for bioanalytical applications. Chem. Rev. 113, 2842-2862 (2013).

40. Liu, J., Cao, Z. \& Lu, Y. Functional nucleic acid sensors. Chem. Rev. 109 1948-1998 (2009).

41. Du, Y., Li, B. \& Wang, E. "Fitting" makes "sensing" simple: label-free detection strategies based on nucleic acid aptamers. Acc. Chem. Res. 46, 203-213 (2013).

42. Pei, H. et al. Reconfigurable three-dimensional DNA nanostructures for the construction of intracellular logic sensors. Angew. Chem. Int. Ed. 51, 9020-9024 (2012).

43. Liang, H. et al. Functional DNA-containing nanomaterials: cellular applications in biosensing, imaging, and targeted therapy. Acc. Chem. Res. 47, 1891-1901 (2014).

44. You, M. et al. DNA "nano-claw": logic-based autonomous cancer targeting and therapy. J. Am. Chem. Soc. 136, 1256-1259 (2014).

\section{Acknowledgments}

This work is supported by the National Natural Science Foundation of China (21275156, $41273093,21175101)$ and the State Key Laboratory of Electroanalytical Chemistry.

\section{Author contributions}

Y.G. designed the experiments, performed the majority of experiments, analyzed results and wrote the paper. L.Z., L.X. and X.Z. performed experiments and analysed results. J.H. supervised the project and analysed results. R.P. supervised the project, analysed results and wrote the paper.

\section{Additional information}

Supplementary information accompanies this paper at http://www.nature.com/ scientificreports

Competing financial interests: The authors declare no competing financial interests. How to cite this article: Guo, Y. et al. Multiple types of logic gates based on a single G-quadruplex DNA strand. Sci. Rep. 4, 7315; DOI:10.1038/srep07315 (2014). 
cc)(i) (2) This work is licensed under a Creative Commons Attribution-NonCommercialShareAlike 4.0 International License. The images or other third party material in this article are included in the article's Creative Commons license, unless indicated otherwise in the credit line; if the material is not included under the Creative
Commons license, users will need to obtain permission from the license holder in order to reproduce the material. To view a copy of this license, visit http:// creativecommons.org/licenses/by-nc-sa/4.0/ 